\title{
THE SOCIAL WORKER'S FUNCTION IN DIVORCE PROCEEDINGS*
}

\author{
EMILY H. MudD $\dagger$
}

Judge Alexander's plan for a new method of handling at an earlier stage requests for divorce and perhaps also other family problems is now familiar to many groups. This proposed plan for court procedure contains a basic requirement, first, that a problem of marital discord should be carefully investigated by a committee of experts before a petition for divorce be permitted to come into the courts, and second, that the court then should be guided in its decision by the recommendations of this committee as to what is for the best interest of the family as a whole.

From the point of view of a social worker and marriage counselor such an attempt appears to be a step well in advance of much current legal court practice. If such a therapeutic approach to the divorce problem should be put into effect, I believe that the social worker and marriage counselor should be a part of this approach and would be able to contribute to it. My assignment is to consider in some detail what this part might be-first in broad context, and second under the reality limitations of present conditions.

Some understanding of the basic tenets of social work should help in orientation to the point of view that social work could contribute to the suggested therapeutic approach to divorce. Social work generically is concerned with human behavior and human relationships. Marriage and divorce are admittedly vital processes in human relationships. Casework, as one branch of social work, prepares its workers primarily to deal with the emotional growth and security of the individual. An emotionally mature and reasonably secure individual can usually handle the run-of-themill problems of marriage and family living. According to Dr. Hertha Kraus, ${ }^{1}$

Social casework has great faith in teamwork and mutual aid and encourages them at all times, whether among clients, family members, or in professional and community relations. Thus, it helps to prepare people to share freely and to enter fully into voluntary ventures in cooperation. ... [It] can make the tenets of democratic living a deeply personal experience.

Many thousands of caseworkers are employed in family, children's, and marriage counseling agencies where maladjustment between the partners, or actual separation and divorce, are the focal point of generalized disturbance or more specific

* A paper presented at the University of Chicago Law School Conference on Divorce, February 29, 1952.

+Ph.D.; Executive Director, Marriage Council of Philadelphia; Assistant Professor of Family Study in Psychiatry, University of Pennsylvania.

1 The Role of Social Casework in American Social Work, 31 Socrat Casework 3, 9 (1950). 
serious distress of body, mind, and soul, for which help is sought. Incidentally, it should be mentioned here and borne in mind throughout this discussion that marriage counseling is here regarded as a specialized field of family counseling which centers largely on the inter-personal relationship between husband and wife. It involves many disciplines and is inter-professional in character. Those who wish to enter this field, however, whether physician, clergyman, psychiatrist or social worker, require a common body of scientific knowledge, techniques, and qualifications. Where marriage counseling is involved, whether by social worker within the general framework of casework, or by members of the other professions most usually involved-psychology, sociology, medicine, or psychiatry-it is generally recognized that special skills, background, and experience over and beyond routine graduate professional training are required for adequate and successful performance on the part of the marriage counselor. There is also general agreement that the purpose of marriage counseling is to help people find their way through the rough spots to a relationship which, hopefully, is constructive for both partners and their children.

Under the conditions just described the classical function of social casework is fulfilled. The social agency, as part of the community, offers a service which is sought by a person in need of help. Using methods of casework or counseling learned through professional training and supervised experience on the job, the worker aids the clients in exploring the problem, understanding their own part in it and that of others closely involved, trying out new attitudes and modes of behavior, relating these in greater degree to reality, and finally arriving at a "selfdetermined" resolution of their difficulties. ${ }^{2}$

From our discussion of social casework, it becomes reasonably clear that the panel of experts suggested in Judge Paul Alexander's new court procedure, should include an experienced caseworker with special training in marriage and family counseling. ${ }^{3}$ This worker should be well equipped to explore with the applicant for divorce his situation as well as that of his partner. Attitudes, feelings, and value systems, as well as behavior patterns and factual material, could be obtained from the applicant and reported to the other committee members, who will consist, supposedly, of a psychologist and a psychiatrist.".

This procedure would be well within the accepted functioning of a caseworker and in itself such a process of survey and exploration of a problem is often found to have therapeutic value and to be of benefit. Certain individuals may even decide

\footnotetext{
${ }^{2}$ Emiry H. Mudd, The Practice of Marriage Counseling, c. X (I95I).

${ }^{3}$ In addition to on-the-job supervised training for case workers in Family Service Agencies which include marriage counseling in their program, specialized in-service training in marrage counseling is available to graduate case workers, clinical psychologists, doctors, and psychiatrists through programs supported by the Grant Foundation at the Marriage Counseling Service of the Menninger Foundation and at the Marriage Council of Philadelphia, affiliated with the School of Medicine, University of Pennsylvania.

'A sociologist would have no functional position on such a committee according to a statement made by Dr. Meyer Nimkoff at the Conference on Divorce held February 29, 1952, by the Chicago Law School, Chicago, Ill.
} 
not to continue their petition for divorce as a result.

This special committee, with this material from the caseworker along with findings from the psychologist and the psychiatrist, will then, presumably, be able to arrive at certain decisions as the specific situation determines.

(I) In some instances it will be apparent that the best interest of the individuals who constitute the family will be served by the separation (or divorce) of the marriage partners.

(2) In some instances, as already mentioned, the very process of exploration will aid an individual or couple voluntarily to withdraw divorce application and to continue in their marriage.

(3) In other instances, the committee may request the couple to try to understand themselves and their relation to each other and marriage more clearly before a valid decision as to what is best for the family can be made.

It is with this third group (probably the largest) that the kernel of the problem lies for the social worker, marriage counselor, and the community. The dilemma cannot be resolved by recommending that the court refer persons in Group 3-those who it is believed need to try counseling before a valid decision can be made-for marriage counseling service to the already existing family service or marriage counseling clinics in the community rather than initiate such a service within the court set-up.

The real dilemma is whether or not casework can contribute or is willing to contribute through the process of counseling when the clients are requested by authority to seek such counseling.

Under conservative scrutiny, certain premises of good casework practice seem at first to be automatically at variance with conditions superimposed by such an authoritarian court approach as just described, under which the applicant for divorce would be required to explore his problem with a counselor. "Unless a person really wants help, there is little chance that anything will happen," is a by-word familiar to caseworkers as well as psychotherapists.

However, if we examine practice in certain community services utilizing caseworkers we find that society steps into this situation in spots and enforces something different. Often a cooperative and apparently constructive relationship is maintained between the caseworker or psychiatrist and the client or patient even when the client comes for service under the pressure of authority. For example, delinquent girls or boys as wards of the court in certain circumstances, are assigned to a community social agency such as a Girls' or Boys' Council or Youth Service. Under these circumstances the agency finds a foster home for the young person and in addition assigns a counselor to supervise and assist the client to growth and more healthy maturity. Remarkable progress can result from such relationships.

In our now famous child guidance clinics, the parent may be self-motivated in seeking help but the child brought by the parent when first seen by the psychiatrist, could hardly in many circumstances be said to come voluntarily because he is 
seeking help. Granted, if he is to receive help, motivation to use it eventually must take place within him and usually does through the skill of an able psychiatrist. One can think also of the acutely ill mental patient who because of the exigencies of the situation, is institutionalized by force and given shock treatment. Later, when introduced to psychotherapy, he may use this actively and contructively, because of the special skill of the therapist, until he is finally cured and released from the hospital. This actually happens to thousands of patients yearly.

These examples indicate that individuals in trouble and difficulty have varying types and degrees of motivation for change and development and that motivation may be attained at different stages of need and at different times of exposure to skilled help. They also indicate that, in spite of theory which indicates that it is useless to undertake treatment unless the person voluntarily wants help, treatment is actually being undertaken at times without the initial willingness of the patient. This approach is being undertaken with many thousands of young people by psychiatrists and social workers in connection with child guidance clinics, institutions for delinquent children and adolescents, school counseling, and other services. It is being done continually with older persons in state and private mental hospitals. It is made necessary because of the reality demands and limitations of the situation. Obviously the conditions are not ideal and presuppose considerably less successful results than under conditions in which the client or patient has a part in seeking help. However, apparently under these far from ideal conditions, when the therapist or caseworker recognizes and accepts the situation, he is able in many instances to handle the severe resistance and defenses presented by the patient or client. And eventually, through the therapist's special skills, he challenges the person and in a proportion of cases finally wins the latter's interest and cooperation.

It is obvious that the conditions just described present an inconsistency between widely accepted theory and certain types of practice and in a measure it is unorthodox to draw attention to this. However, the ability of the well-trained, experienced marriage counselor (be this counselor's background in psychiatry or casework) to use his skills to challenge and enlist the cooperation of the person who finds himself in a painful marriage situation not to his liking has been illustrated in work with partners in the same marriage. In such work, the initial contact is often made by only one of the partners and the second partner may be contacted because he is a part of the marriage. The latter often continues his contact because, through the skill of the counselor, he realizes he also has a stake in the outcome of the marriage.

On the basis of this experience I would like to hypothesize that if the experienced and skilled marriage counselor could accept, as an inevitable part of a reality situation, the resistances engendered in his client by a court requirement that the latter discuss his problem with a counselor before his petition for divorce can be permitted, and if the counselor can work successfully with these resistancesa number of clients would decide to use assistance and would do so with benefit 
to their marriage. This of course does not mean that the chances of being of help in marital adjustment may not be greatly enhanced by working on the situation before it has come to court rather than after. However, even under the more ideal conditions of voluntarily sought help in marital conflict, marriage counseling services admit the failure of their efforts in a proportion of cases. Figures available in two attempts at evaluation of service by different methods estimate approximately 60-75 per cent of cases showing a partial or definite improvement (Hollis, and Hukman and Stone). In a group of 2II cases analyzed in detail at the Marriage Council of Philadelphia under a grant from the United States Public Health Service, $6_{3}$ per cent show positive movement during counseling, 27 per cent showed no movement, 5.5 per cent had insufficient data, and 4.5 per cent revealed retrogression. Although research is underway at the Marriage Council of Philadelphia to establish some factual basis for predicting the response to counseling, it is as yet too new and unrepeated to effect the present trial and error method of accepting cases in community services. Therefore there is little choice but to offer service even if failure to use it or from its use ensues.

Additional current research is proffering definite information on the kinds of problems, conditions, attitudes, and values of clients seeking marriage counseling, which correlate with positive or constructive use of counseling. If predictive tools enabling counselors to attempt judgments as to the probability of success of individual clients in utilizing treatment become even in small measure practical, the time of the skilled counselor can be used more consistently with those clients whose prognosis for making use of counseling is good.

In conclusion, it is often contended that the most prevalent reasons for divorce are the childishness, lack of maturity, or lack of realism of one or both marriage partners. If these contentions are correct, how can we expect the most childish, immature, and unrealistic individuals voluntarily to seek help? Experienced marriage counselors usually agree that it is the more realistic, stronger, and better adjusted of the partners in a sick marriage who initiates contact with a counseling service and bears the brunt of the difficulties at home. Often the more childish partner is first motivated to seek counseling through his partner's activity. He feels left out-that he is missing something. If the motivation, no matter what its basis, is utilized by the counselor, progress may result.

If both partners to a marriage are, emotionally speaking, children, spoiled and stunted in development, can social casework and marriage counseling aid them in their growing under these new conditions which, at first thought, seem to violate time honored precedent? I should like to answer this question with another. If any of us, lay or professional, see two ten year old children biting, scratching, and beating each other to the extent of serious harm to both, do we leave them to destroy each other until they voluntarily ask someone to help them stop? No, of

\footnotetext{
'Preston, Mudd, Froscher, and Peltz, Research in Casework (paper presented at National Conference of Social Work, May 27, r952, Chicago, Ill.); CAsEwork (in press, 1952).
} 
course we don't! Then why should casework or any other arm of society remove its possibilities of assistance from the thousands of, emotionally speaking, ten year olds who through ways and means more devious than the mythical labyrinth of old are destroying each other in marriage cruelly, painfully, and often unknowingly and unwittingly? It is my conviction, to which others may or may not agree, that social workers and other marriage counselors have a great deal to contribute to the type of court situation recommended by Judge Alexander, both as members of the exploratory committee and in the treatment of those marriages which, as the Judge says, are still viable or have a spark of life.

But do not let us fool ourselves or overestimate the degree to which social work or, if I may say so, any of the other so-called "helping" professions can solve the problem of divorce in our society, if we limit ourselves to survey, exploration, and even treatment at the time the pair of married "partners" are bruised, cut, and perhaps mortally wounded. Judge Alexander's crusade is epoch-making. It stirs the complacency of our professional patterns in asking whether we can use ourselves under a different set of conditions. It may also stir us to question the roots of this social dilemma and to seek more adequate preparation and safeguarding of the institution of marriage itself. Perhaps eighteen or twenty-one years should be measured by more than a birth certificate before a marriage license is issued by our states? 